\title{
ARTIGO
}

DOI: $\underline{\text { https://doi.org/10.22481/praxis.v15i31.4670 }}$

\section{A LITERATURA INFANTIL EM SITES EDUCATIVOS: A QUALIDADE DOS SITES E A ESTÉTICA DOS TEXTOS}

\author{
THE CHILDREN'S LITERATURE IN EDUCATIONAL SITES: THE QUALITY OF THE \\ SITES AND THE AESTHETIC OF THE TEXTS
}

\author{
LA LITERATURA INFANTIL EN SITIOS EDUCATIVOS: LA CALIDAD DE LOS \\ SITIOS Y LA ESTÉTICA DE LOS TEXTO
}

\author{
Eliane Santana Dias Debus \\ Universidade Federal de Santa Catarina - Brasil \\ Elika da Silva \\ Universidade Federal de Santa Catarina - Brasil
}

\begin{abstract}
Resumo: $\mathrm{O}$ artigo busca, a partir dos critérios de análise de sites educativos propostos por Carvalho (2006) e da categoria linguagem verbal, analisar a configuração dos sites educativos que trazem a temática da literatura infantil, verificando como o literário se evidencia no texto de literatura infantil online. Entendemos que a leitura literária é de grande importância para a vida das pessoas e por meio dela conseguimos interagir com o mundo a nossa volta e também acreditamos na importância dessa literatura em diálogo com as mídias digitais para a formação do leitor, por isso se faz imprescindível a análise do material que está ao alcance das crianças. Constatou-se que a literatura infantil online pode ser uma aliada na formação do leitor, porém, nos sites brasileiros e gratuitos analisados na pesquisa, percebemos, em alguns casos, que o texto de literatura infantil online se apresenta sem as características de interatividade com o leitor e inovação que esse meio possibilita.
\end{abstract}

Palavras chaves: Sites educativos; Literatura infantil; Tecnologia digital; Formação do leitor.

\begin{abstract}
This paper reports on the results of a study aimed to analyze educational website configuration presenting children's literature to investigate how it is portrayed. In this sense, an attempt was made to unveil which aspects can be considered relevant in the selection of educational websites that offer literary content for early Elementary School students, which may enhance their literary development as well as diversify their contact with literature on digital media. Three websites were selected and divided into the following categories: authors, works, and educational websites, and they were primarily analyzed based on criteria put forward by Carvalho (2006), and later on based on literariness. On free Brazilian websites, it was possible to observe that, in some cases, the text is presented in a non-creative fashion, lacking innovation and interactivity with the reader or user.
\end{abstract}

Keywords: Education websites; Children's literature; Digital technology; Reader development.

Resumen: El artículo busca, a partir de los criterios de análisis de sitios educativos propuestos por Carvalho (2006) y de la categoría lenguaje verbal, analizar la configuración de los sitios educativos 
que traen la temática de la literatura infantil, verificando cómo el literario se evidencia en el texto de literatura infantil en línea. Entendemos que la lectura literaria es de gran importancia para la vida de las personas y por medio de ella conseguimos interactuar con el mundo a nuestro alrededor y también creemos en la importancia de esa literatura en diálogo con los medios digitales para la formación del lector, por eso se hace imprescindible el análisis del material que está al alcance de los niños. Se constató que la literatura infantil online puede ser una aliada en la formación del lector, pero en los sitios brasileños y gratuitos analizados en la investigación, percibimos, en algunos casos, que el texto de literatura infantil online se presenta sin las características de interactividad con el " lector e innovación que ese medio posibilita.

Palabras claves: Sitios educativos; Literatura infantile; Tecnología digital; Formación del lector.

\section{Introdução}

O presente artigo apresenta discussões de pesquisa de mestrado desenvolvidas no âmbito do Programa de Pós-Graduação em Educação da Universidade Federal de Santa Catarina (UFSC), cujo objetivo foi analisar a configuração dos sites educativos que trazem a temática da literatura infantil (LI) verificando como o literário se evidencia. Desse modo, procuramos entender quais aspectos podem ser considerados relevantes na seleção de sites educativos que focalizam a leitura literária.

O referencial teórico levou em conta o estudo de Carvalho (2006), que orienta a análise dos sites por meio da utilização das categorias, assim como estudiosos que tratam da especificidade da literatura infantil no espaço escolar, bem como aqueles que se debruçam sobre as Tecnologias Digitais da Informação e Comunicação (TDICs) e sobre a ótica da importância dessa união (literatura e tecnologia) estar presente nesse espaço, entre eles: Zilberman (2003), Azevedo (1999), Hunt (2010), Cunha (2008, 2009), Amarilha (2012), Santaella (2004), Rettenmaier (2009), entre outros.

Para a seleção dos sites foi enviado um questionário para os vinte e sete (27) professores auxiliares de Tecnologia Educacional que atuam nas Salas Informatizadas das escolas da Rede Municipal de Educação de Florianópolis (SC). A partir desse questionário foram divididos os sites nas categorias autores, obras e educativos, para melhor agrupá-los para análise. Dentre eles, escolheu-se um de cada categoria para analisar a partir dos critérios propostos por Carvalho (2006), que levanta as seguintes dimensões de qualidade de um site educativo: identidade, usabilidade, rapidez de acesso, níveis de interatividade, informação, atividades, edição colaborativa online, espaço de partilha e comunicação. Para a análise das especificidades dos textos literários online, criou-se a categoria linguagem verbal a partir do referencial teórico utilizado na pesquisa, que diferencia um texto infantil online de um texto 
de LI online. Ou seja, verificamos como se apresentam os textos encontrados na internet, buscando um diálogo entre a qualidade e a estética ${ }^{1}$ dos textos literários online. Dessa maneira, na categoria autor, o site escolhido foi da autora Angela Lago (www.angelalago.com.br); na categoria obra, escolhemos o site Menino Maluquinho (www.meninomaluquinho.com.br) e, por último, na categoria educativo, foi selecionado o site O pequeno leitor (www.pequenoleitor.com.br).

\section{Sites educativos: formação de leitores literário}

Mediante a diversidade de práticas sociais de leitura e escrita presentes na sociedade da informação e comunicação, acreditamos ser importante refletir sobre o perfil do leitor contemporâneo. Por isso, buscamos conceituar e apresentar algumas considerações sobre as novas formas de leitura que as tecnologias digitais oferecem, assim como a necessidade de novas habilidades de leitura, pelas quais ele navega nas páginas da internet com competências de leitura diferenciadas do livro impresso.

Devido às transformações sociais, vivemos um momento em que as formas de aprender são variadas. Faz-se necessário, pensar e refletir os espaços que as Tecnologias Digitais da Informação e Comunicação (TDICs) ocupam na escola e qual a melhor forma para utilizá-las como ferramenta que possam auxiliar no processo de ensino aprendizagem. O perfil do leitor contemporâneo passa por transformações, pois os atuais suportes das TDICs colocam a disposição deles diferentes leituras nos meios digitais, por meio de links, imagens, vídeos, entre outros, em que pode interagir com o texto e, em muitos casos, modificar e/ou percorrer caminhos diferentes, de acordo com seu interesse e as possibilidades que a internet oferece. Santaella (2004) destaca que existem três tipos de leitores que convivem em harmonia: o contemplativo, o movente e o imersivo. Portanto, o leitor foi se ajustando as novas possibilidades de leituras, formando o leitor imersivo que navega nas páginas da internet.

Sabe-se que quando nos deparamos com o teclado e a tela em branco do computador é o "resultado de um percurso de transformações tecnológicas dos recursos da escrita: do registro na pedra ao hipertexto da era digital” (DEBUS, 2008, p. 38). As modificações

\footnotetext{
${ }^{1} \mathrm{O}$ conceito de estética destacado neste artigo é utilizado por Hunt (2010) e Azevedo (1999) quando defendem que a principal preocupação com o texto de LI deve ser com a qualidade da linguagem escrita, que deve servir como fruição estética, ou seja, a literatura como arte em que sua única utilização deve ser a busca pelo prazer da leitura.
} 
histórico-sociais influenciam e transformam as relações entre as pessoas e os produtos culturais. A história da escrita mostra-nos como o uso de recursos foram os mais variados possíveis, pois até chegar ao hipertexto, utilizamos diferentes sistemas de escritas (pictográfico, ideográfico, alfabético).

A história da literatura não foi diferente, pois se era tão difícil o ato de escrever, adquirir um livro era possível apenas pelas classes dominantes. No texto Sobre a literatura, Umberto Eco (2003, p. 9) destaca que o livro antes de ser de "papel” era acessível apenas pela voz de quem os guardava na memória ou "mesmo na pedra" e que hoje discutimos o "futuro dos e-books". Então, durante muito tempo a leitura foi uma prática de demonstração de poder, progressivamente ocorreu uma transformação de pensamentos e hoje temos livros dos mais variados gêneros, formatos e suportes, como o disponível na web.

A LI também sofreu transformações, sua origem teve um fim direcionado. No século XVIII, devido a uma nova noção de família, houve uma mudança de tratamento e uma nova compreensão de infância. Segundo Zilberman (2003, p.15), “[...] inexistia uma consideração especial para com a infância. Essa faixa etária não era percebida como um tempo diferente, nem o mundo da criança como um espaço separado". Logo, não seria necessária uma literatura específica para este público. Entretanto, a noção de família gerou o cuidado e a preocupação com a infância, surgindo a escola e produtos culturais para ela, entre eles a LI, com o intuito de passar ideais e valores nos quais a organização social da época se fundamentava.

Zilberman (2003, p. 34) observa que:

Para conceituar-se a literatura infantil, é preciso proceder a uma consideração de ordem histórica, uma vez que não apenas o gênero tem uma origem determinável cronologicamente, como também seu aparecimento decorreu de exigências próprias da época [...] as ascensões respectivas de uma instituição como a escola, de práticas políticas, como a obrigatoriedade do ensino e a filantropia, e de novos campos epistemológicos, como a pedagogia e a psicologia, não apenas inter-relacionadas, mas uma consequência do novo posto que a família, e respectivamente a criança, adquire na sociedade. É no interior dessa moldura que eclode a literatura infantil.

É importante destacar que a história da LI no Brasil tem início no final do século XIX, mas a produção de uma literatura voltada para o público infantil brasileiro só se consolida no século XX, quando o país começa a produzir sua própria literatura e tem a preocupação “de abrasileirar a linguagem dos textos escritos para crianças vindos de fora, para torná-los mais 
atraentes" (PERROTTI, 1986, p. 57), ou seja, uma literatura brasileira que destacava nossas condições sociais e culturais.

O livro impresso para crianças que circula no mercado editorial brasileiro contemporâneo, por certo não é o mesmo do início do século XX, não só em relação ao seu conteúdo, mas a sua forma: ilustração colorida; tipo de papel e formato, o aspecto gráfico da obra é uma preocupação cada vez mais constante em sua produção, permitindo a criança um encontro lúdico com o livro.

Aparentemente linear, o livro impresso também permite a interatividade e a partir da era digital ganha mais espaço, com textos inovadores que permitem a participação do leitor, uma vez que pode decidir que caminho seguir durante a leitura e que, de acordo com Debus e Domingues (2015, p. 72), “de certa forma dão aos leitores a sensação de serem eles também autores da história, na medida em que podem decidir o fim ou o percurso da narrativa", tornando a leitura mais interessante e dinâmica. Nesse cenário, o leitor contemporâneo convive com uma diversidade de livros produzidos em diferentes formatos e suportes.

Sendo assim, Cunha (2008, p. 49) afirma que "diversos códigos migram para o livro, da mesma forma como códigos do livro migram para outros suportes, e, com este trânsito, os textos vão assumindo características de estrutura hipertextual”. Portanto, é necessária a compreensão de novas formas de linguagem e leitura que vão além do código verbal, ou seja, a leitura nos meios eletrônicos.

A literatura não se apresenta somente no impresso, ela está disponível online, num formato que permite ao leitor brincar com as páginas animadas num simples toque com o mouse, ou ao toque dos dedos (touchscreen), no caso dos tablets, smartphones e outros, e com a facilidade de acesso por meio da internet a uma gama de produções no meio virtual, em que as imagens, páginas, e-books, blogs, jogos, redes sociais e demais locais da rede podem ser facilmente acessados e manipulados com estruturas labirínticas que requer um leitor capaz de interagir e escolher caminhos a serem percorridos. O perfil desse leitor, que vive conectado com o mundo da comunicação e informação, não é o mesmo do século passado. Portanto, para que o acesso ao espaço virtual da leitura aconteça, numa perspectiva de fortalecer o contato com os textos literários, é preciso domínio da leitura e práticas de navegação.

E nesse contexto, o papel da escola e dos educadores de acordo com Amarilha (2012), é fundamental para que as novas gerações se beneficiem de uma maneira crítica das TDICs. Mas é preciso um novo olhar sobre as práticas educativas, pois, esses estudantes nativos das tecnologias digitais, precisam de educadores qualificados para que "potencializem suas 
habilidades recém-emergentes e os tornem argutos selecionadores dos materiais aos quais são expostos" (Amarilha, 2012, p.7).

A leitura "navegativa" possibilita que o leitor navegue nas páginas da internet interagindo pelos links que tem movimentos, sons e imagens, se apresentando como participante ativo no ato da leitura, às vezes deixando marcas no próprio texto, de acordo com sua vontade e expectativas, nas infinidades de textos e possibilidades que tem a sua disposição, caracterizando a interação leitor e texto que Santaella (2004, p.31) define como "leitor imersivo", ou seja, aquele que "navega entre nós e conexões alineares pelas arquiteturas líquidas dos espaços virtuais”. A leitura navegativa de infinitas possibilidades exige do leitor uma seleção para não se perder no meio digital.

Conforme Santaella (2004), o perfil do leitor imersivo é mais livre na medida em que pode escolher o caminho a seguir, e esse novo leitor da cibercultura esta imerso no mundo virtual. Ou seja, ele escolhe as possibilidades de leitura, da mesma maneira que suas escolhas podem encontrar desafios que precisam ser enfrentados, caracterizando uma nova forma de entender a leitura no mundo virtual. A autora ainda destaca que a hipermídia é marcada pela interatividade, e o leitor não pode usá-la de modo passivo, isto é, quanto mais interatividade, maior será a experiência dele com concentração, atenção e compreensão da informação. Enfim, a LI contemporânea, tanto no impresso como nos meios digitais, abre caminhos para novas formas de leituras com infinitas possibilidades e significações.

\section{Critérios de análise de sites educativos: Ana Amélia Amorim Carvalho}

Escolhemos como referência os critérios propostos por Carvalho (2006), pois suas pesquisas são relacionadas à qualidade de sites educativos, em que levanta critérios de análise que consideramos importantes, além de seus estudos centrarem na utilização das tecnologias da informação e da comunicação com base na aprendizagem dos estudantes.

A autora no texto Indicadores de Qualidade de Sites Educativos (CARVALHO, 2006) destaca que existe uma diversidade muito grande de informação no World Wide Web (mais conhecido como www), que cresce a cada dia, com muita liberdade de publicação online. Desse modo, é fundamental que o cibernauta domine a navegação na internet.

Carvalho (2006) considera pertinente para a escolha de sites educativos noves critérios de qualidade, sendo eles: Identidade, usabilidade, rapidez de acesso, níveis de interatividade, informação, atividades, edição colaborativa online, espaço de partilha e comunicação. De acordo com a autora, eles se entrecruzam dependendo do usuário, contribuindo para as 
dinâmicas de interatividade e de responsabilização na aprendizagem, assim como na produção de trabalhos. Para chegar a estes critérios a autora se baseou na Norma ISO/IEC 9126-1 (2001), em uma revisão de literatura e na sua experiência na análise de sites. No quadro a seguir, apresentamos uma síntese desses critérios.

Quadro 1: Síntese dos critérios de qualidade de um site educativo

\begin{tabular}{|c|c|}
\hline Identidade & $\begin{array}{l}\text { A identidade de um site é justamente o nome dele, assim como se o site } \\
\text { apresenta seu propósito ou finalidade, a autoridade, a data de criação e } \\
\text { da última atualização, entre outras informações que possam ajudar o } \\
\text { usuário a se orientar sobre as páginas. (Carvalho, 2006, p.18) }\end{array}$ \\
\hline Usabilidade & $\begin{array}{l}\text { A usabilidade de um site significa se ele é fácil de usar e fácil de } \\
\text { aprender a usar, assim como se o usuário fica satisfeito ao utilizá-lo. Se } \\
\text { as páginas contribuem para a compressão da estrutura do site, como } \\
\text { navegação e orientação, os aspectos gráficos, se apresenta menu para } \\
\text { orientar o usuário nas seções do site. (Carvalho, 2003, p. 20) }\end{array}$ \\
\hline Rapidez de acesso & $\begin{array}{l}\text { A rapidez de acesso e hiperligações }(\text { links) eficazes, contribuem a } \\
\text { facilidade de navegação, são atrativos e deixam o navegador satisfeito, } \\
\text { no entanto, se as hiperligações forem quebradas dificultando o acesso } \\
\text { as páginas deixam o utilizador insatisfeito. (Carvalho, 2006, p.21) }\end{array}$ \\
\hline $\begin{array}{c}\text { Níveis de } \\
\text { interatividade }\end{array}$ & $\begin{array}{l}\text { A interatividade de um site educativo deve ser desafiadora, com o } \\
\text { objetivo de motivar o usuário a explorar as páginas. (Carvalho, 2006, } \\
\text { p. 21) }\end{array}$ \\
\hline Informação & $\begin{array}{l}\text { As informações disponibilizadas podem estar em qualquer formato, } \\
\text { como textos, imagens, sons e vídeos. O importante é a informação } \\
\text { apresentar o conteúdo de forma compreensiva para o estudante, assim } \\
\text { como, as ajudas e as perguntas frequentes (FAQs). (Carvalho, 2006, } \\
\text { p.22) }\end{array}$ \\
\hline Atividades & $\begin{array}{l}\text { As atividades dos sites devem ter como principal objetivo levar os } \\
\text { estudantes a conhecerem a informação nele disponível, ou se for o caso } \\
\text { deve disponibilizar links de sites afins. (Carvalho, 2006, p.23) }\end{array}$ \\
\hline $\begin{array}{c}\text { Edição colaborativa } \\
\text { online }\end{array}$ & $\begin{array}{l}\text { Edição colaborativa online acontece quando o site educativo } \\
\text { disponibiliza ferramentas colaborativas online (blogues, wiki, chats) } \\
\text { permitindo que vários usuários de diferentes localidades, desde que } \\
\text { exista conexão à internet, consigam colaborar para um mesmo projeto } \\
\text { ou atividade. (Carvalho, 2006, p.24) }\end{array}$ \\
\hline Espaço de partilha & $\begin{array}{l}\text { O espaço de partilha é um espaço em que podem ser disponibilizados } \\
\text { os trabalhos realizados pelos estudantes ou pelos professores. } \\
\text { (Carvalho, 2006, p.24) }\end{array}$ \\
\hline Comunicação & $\begin{array}{l}\text { Um site educativo além de disponibilizar o contato do responsável para } \\
\text { esclarecimento de dúvidas deve ter um espaço de discussão (fóruns, } \\
\text { chats) para que motive os usuários a utilizar novamente o site. } \\
\text { (Carvalho, 2006, p.25) }\end{array}$ \\
\hline
\end{tabular}

Fonte: Elaborada pela pesquisadora, síntese com base no artigo de Ana Amélia Amorim Carvalho (2006).

Os indicadores de qualidade apresentados, de acordo com Carvalho (2006), estão diretamente relacionados com as tecnologias digitais atuais. Destacando o papel das TDICs como motivadoras da aprendizagem, sendo que as ferramentas disponíveis na web podem ser de grande ajuda nesse processo, pois podem incentivar a construção colaborativa, a edição e 
publicação, além de ser uma ferramenta atrativa, que os estudantes têm bastante facilidade de manuseio.

\section{Critérios de análise de texto literário online: Linguagem verbal}

Na contemporaneidade a LI se apresenta com grande diversidade de títulos, com temas focalizando diferentes contextos sociais e culturais, bem como sua publicização em suportes variados, como na internet em formato eletrônico, possibilitando ao leitor o encontro ampliado com a leitura literária. Para estudar a literariedade dos textos online, torna-se necessário levantar algumas considerações a respeito do texto literário para criança. Não temos a pretensão de definir o conceito de LI, pois como afirma Hunt (2010) não pode haver uma definição única de "literatura infantill", o único elemento que a define é o leitor e sua relação com o texto literário.

Hunt (2010) defende que a LI não pode ser entendida como inferior, é preciso pensar o texto literário numa perspectiva que se aproxime das demais literaturas. Entendemos que para distinguir a diferença entre livro para criança e livro de literatura infantil, a principal preocupação na escolha de qual texto escolher, deve ser a qualidade da linguagem escrita, pois o autor explica que simplificar o texto para o público infantil, ao contrário do que se pensa, não ajuda, e, sim, desestimula. O texto deve servir, então, como fruição estética e não para fins moralizantes e/ou imprimir comportamentos à criança. $\mathrm{O}$ autor defende ainda que o essencial é perceber a criança como leitora em desenvolvimento.

Ricardo Azevedo (1999), preocupado com a homogeneização dos livros, propõe uma classificação geral para as diversas obras de recepção infantil, produzidos pela indústria editorial. Porém, destaca que todas as categorias de livros são importantes, têm seu espaço conceitual e sua razão de ser, mas precisam ser categorizados para não gerar confusão aos leitores e mediadores de leitura. Além de acreditar que a indiferenciação entre os inúmeros tipos de obra pode afastá-los do texto literário.

O autor faz uma importante categorização para separar os livros de LI, de outros que utilizam o objeto livro como suporte, elencando seis categorias, sendo elas: livro didático, livros paradidático, livros jogos, livros imagens, CD-ROM e livros de literatura infantil. Em cada categoria o autor destaca sua especificidade, sendo o livro didático como essencialmente utilitário, servindo exclusivamente para fins pedagógicos. Os livros paradidáticos também servem para fins pedagógicos, de forma a complementar o livro didático. Livros jogos não 
tem literariedade. Já os livros imagens, podem ter literariedade ou não. Na categoria CD-rom, o autor destaca como suporte para literatura, porém de vida curta devido aos avanços da internet, constata-se realmente que o CD-rom ficou obsoleto com a difusão da internet. No entanto, foi uma importante ferramenta, principalmente para as escolas quando começaram a inserir as tecnologias digitais para os estudantes e não havia o recurso da internet.

$\mathrm{Na}$ categoria livros de literatura infantil, Azevedo (1999, p.5) evidencia a literatura como arte que, feita de palavras, utiliza sempre o recurso da ficção, tem motivação e estética, sua única utilização é buscar “o belo, o poético, o lúdico e o prazer do leitor”. Não é, portanto, utilitária, pelo contrário, "ela pode falar de qualquer tema, todos os abordados pelos paradidáticos, por exemplo, desde que o mesmo seja visto pelo ângulo da ficção, da subjetividade e da poesia" (Azevedo, 1999, p.5).

O autor chama a atenção para o fato de que a escola, muito mais que ensinar, deve possibilitar o contato do leitor com uma linguagem "expressiva, renovada e poética. A confusão entre a arte (e a ficção) e o didatismo utilitário costuma ter o perverso dom de afastar as pessoas, independentemente de faixas etárias, da leitura e, principalmente, da literatura" (Azevedo, 1999, p.7). Miall e Kuiken (1999, p.1, tradução nossa) também criticam a leitura de literatura vinculada a objetivos de promoção de uma ideologia particular, pois eles afirmam que assim, "qualquer coisa pode ser literatura" ou "pode deixar de ser literatura" dependendo da teoria dominante em cada período histórico e social. Os autores destacam que existem características especiais que diferenciam o texto literário de outros textos. Com base nas discussões desses autores e no artigo de Debus e Balsan (2016), que apresentam a diferença entre o livro infantil e livro de literatura infantil, defendem que o compromisso do primeiro é com os aspectos pedagógicos e curriculares e não com a ficcionalidade do texto literário. Souza (2015) partindo da proposta das autoras destaca duas categorias para os livros destinados às crianças, sendo:

Livro infantil: todo livro produzido para crianças com caráter utilitário e/ou pedagógico, vinculados explicitamente a conteúdos curriculares.

Livro de literatura infantil: todo livro produzido para crianças cuja leitura proporcione: linguagem; estranhamento e reinterpretação (Souza, 201

Sendo que a linguagem deve proporcionar "interação verbal intensa, uma imersão profunda ao universo da linguagem", o estranhamento é a "ampliação das formas singulares de ver e aprender o mundo e aquilo que o constitui" o texto literário com conteúdos que desafiam e transformam ideias "pré-concebidas sobre o mundo" causando o estranhamento e 
novas formas de compreensão do texto literário. E a reinterpretação, é a "desconstrução das referências convencionais, apresentando um convite às mudanças de interpretação" (Souza 2015, p.101), ou seja, um deslocamento, distanciamento ou aproximação do leitor para diferentes interpretações sobre um mesmo tema. Portanto, para um livro ser considerado de LI, deve conter esses componentes de literariedade. Eles podem aparecer separadamente de acordo com as variações linguísticas e narrativas, no entanto, essa sugestão de literariedade é a interação entre esses componentes. Indiferentes das práticas ou funções que podem implicar o uso do texto literário.

Dessa forma, para além das reflexões sobre a importância da literatura, neste caso, especificamente, para o público infantil, a proposta aqui é pensarmos nas TDICs como possibilidades da ampliação de acesso a leitura e de experiência estética com o texto literário, pois entendemos que a literariedade presente nos livros impressos também/devem se apresentar nos textos literários online, e que sua linguagem visual, ou seja, texto escrito, imagens fixas e em movimentos, expressa pela ilustração ou pelo aspecto gráfico, é significativa com valor literário (SOUZA, 2015).

Em geral, as categorias literárias que mencionamos até aqui, serviu de referência na produção de um grupo de categorias sobre literariedade dos textos para a infância, que consideramos importantes para nos apoiar nas análises das especificidades dos textos literários online. Para tanto, nos apoiamos, além de Hunt (2010) e Azevedo (1999), em outras duas categorias destacadas por Souza (2015), a saber: livro infantil e livro de literatura infantil, que foram importantes referências na divisão entre os textos que têm literariedade e os que não têm, dos títulos encontrados nos sites educativos analisados. A partir disso, as categorias servem para a identificação das formas de linguagem escrita encontradas nos sites educativos, e suas implicações nos textos literários online produzidos para a infância. As possibilidades que um texto literário oferece de "linguagem, estranhamento e reinterpretação" (SOUZA, 2015, p.101) são fundamentais para a formação do leitor iniciante.

Assim, defendemos a linguagem literária compreendida como arte, sendo seu compromisso com a ficcionalidade e estética do texto escrito. Da mesma forma, entendemos os textos literários online e suas especificidades permitidas com as TDICs, não como suporte, mas como ferramenta de aproximação do leitor com o texto, configurando um novo formato de leitura em que ele interage e interfere na produção da obra literária.

Neste cenário, o espaço virtual pode ser uma estratégia a mais para potencializar o encontro do leitor em formação com o texto literário. É nessa compreensão que criamos a 
categoria linguagem verbal, para melhor analisarmos a literariedade dos textos online encontrados nos três sites educativos selecionados. Vale ressaltar que, apesar da linguagem verbal e linguagem visual terem aspectos e elementos diferentes, consideramos que no conjunto da obra literária para a infância online, elas precisam estar em diálogo para envolver o leitor. Portanto na análise dos três sites, a linguagem visual, será analisada em sua harmonia com o texto literário, e no caso da ausência da linguagem escrita, será analisada nos aspectos gráficos e consistência da interface, além dos já definidos no critério de usabilidade destacado por Carvalho (2006) se a linguagem visual é significativa e tem literariedade.

Como já destacado por Souza (2015), podemos pensar os textos produzidos para a infância, a partir das categorias: livro infantil e livro de literatura infantil. Partindo dessa compreensão, também podemos pensar em texto infantil online, ou seja, o texto produzido para criança com fins moralizantes e/ou didáticos; e texto de literatura infantil online, que são aquele que tem literariedade, a poeticidade, o estranhamento, a reinterpretação, entre outros. No quadro 2, apresentamos a categoria linguagem verbal e suas especificidades quanto as diferenças dos textos de recepção infantil.

\section{Quadro 02: Categoria de análise dos textos de literatura infantil online}

\begin{tabular}{|c|c|c|}
\hline Categoria & Texto infantil online & Texto de literatura infantil online \\
\hline $\begin{array}{l}\text { Linguagem } \\
\text { verbal }\end{array}$ & $\begin{array}{l}\text { *Linguagem } \\
\text { vinculada às propostas } \\
\text { fragmentadas da leitura } \\
\text { escolarizada, com fins } \\
\text { utilitários e imprimi } \\
\text { comportamentos na criança. } \\
\text { *Suas conexões são lineares } \\
\text { como no livro impresso. } \\
\text { *Imagens e efeitos sonoros } \\
\text { descontextualizados com a } \\
\text { linguagem verbal. }\end{array}$ & $\begin{array}{l}\text { guagem escrita deve ser expressiva, renovada e } \\
\text { poética (AZEVEDO, 1999). } \\
\text { rciona linguagem, estranhamento e reinterpretação } \\
\text { (MIALL, KUIKEN, 1999; SOUZA, 2015). } \\
\text { or é convidado a interagir }{ }^{2} \text { com o texto e contribuir } \\
\text { com a produção do mesmo e/ou escolher caminhos } \\
\text { diversos para finalizar a história, estabelecendo sua } \\
\text { co-produção do texto. (CUNHA, 2009). } \\
\text { eratividade deve contribuir para a compreensão do } \\
\text { texto. Suas conexões não são lineares, ou seja, não } \\
\text { seguem caminhos tradicionais previsíveis. } \\
\text { ecursos suplementares (imagens fixas e em } \\
\text { movimentos, animação e efeitos sonoros) devem } \\
\text { estar em harmonia com o texto literário para } \\
\text { potencializar a leitura do usuário em formação. }\end{array}$ \\
\hline
\end{tabular}

Fonte: Quadro elaborado pela pesquisadora.

\footnotetext{
${ }^{2}$ No critério interatividade, além dos aspectos já apontados por Carvalho (2006), complementamos com os aspectos sobre o texto literário online com suas especificidades que vinculam a interatividade, uma vez, que acontece a interação entre leitor/autor.
} 
Destacamos até o momento importantes aspectos sobre o texto literário, literatura infantil, literatura digital e leitor navegador; além dos estudos sobre os critérios de análises de sites educativos e da categoria linguagem verbal. Dessa forma, as análises foram realizadas com um olhar atento e crítico, pois, partindo dos estudos que realizamos, percebemos que o meio virtual e seus recursos podem ser, se bem produzidos e utilizados, uma excelente ferramenta para incentivar de forma significativa o contato da criança com o texto literário.

\section{O site de Angela Lago na categoria autores}

$\mathrm{Na}$ categoria autores escolhemos para analisar o site [http://www.angela-lago.net.br] da autora Angela Lago, que foi criado no período de 1996 e 1998, em parceria com estudantes de diferentes escolas. A autora se interessou pelas mídias digitais na década de 1990 unindo esses recursos com suas técnicas de pintura utilizadas para ilustrar suas histórias. Encontra-se no site obras produzidas especialmente para a internet, com efeitos visuais, sonoros e narrativas que envolvem os usuários com interatividades e jogos de alfabetização. Encontra-se ainda o link com a clássica história de Chapeuzinho Vermelho, que ganha versões variadas a partir da continuidade dada pelo usuário que tem que interagir clicando nas imagens. As escolhas levam a versões diferentes da narrativa, fazendo voltar ao início da história, portanto, só se consegue terminar a história aparentemente, por isso o nome que a autora deu a história é A interminável Chapeuzinho.

Existe no site de Angela Lago um caminho de descobertas da literatura infantil com imagem, som, movimento e interação, com potencialidade de sensibilizar o leitor iniciante para a leitura literária. Percebemos durante a análise as possibilidades dos recursos digitais utilizados que convidam o navegador a participar da história, escolhendo outras possibilidades de finalizá-la com diversos caminhos possíveis, estabelecendo a interação entre leitor/autor. Nesse sentido, Hunt (2010) aponta que as novas formas de histórias encontradas nos textos online, não se pautam nas regras de narrativas com personagens, espaço, atmosfera, tema ou motivo, o texto literário online assume formas, sons, vozes, músicas, ou seja, a interação entre o leitor virtual e a obra de forma não linear com infinidades de possibilidades de leitura.

\section{O site Menino Maluquinho na categoria obras}

$\mathrm{Na}$ categoria obras escolhemos o site [www.meninomaluquinho.com.br] Menino Maluquinho. Acompanhando a revolução das tecnologias digitais, em 2002 foi criado o site 
educativo Menino Maluquinho em que se encontra a versão online do livro original $O$ Menino Maluquinho, título de maior sucesso de Ziraldo Alves Pinto, lançado em 1980, especialmente adaptada para a internet. Existe no site um conjunto de atividades educativas com o objetivo de levar os usuários a conhecerem as informações, com imagens, sons e movimentos, no entanto, com relação ao aspecto gráfico, percebemos os textos com fontes em tamanhos pequenos, sem a possibilidade de o leitor navegador aumentá-las ou modificá-las de acordo com suas necessidades de leitura.

Quanto à linguagem verbal disponível no site, entendemos que ela não se apresenta inovadora e não proporciona estranhamento e reinterpretação (MIALL; KIEKEN 1999; SOUZA, 2015), pois nos textos disponíveis no site, nos links "história do dia", "tirinha", “profissão" e "piadas", percebemos propostas fragmentadas da leitura escolarizada com conexões lineares, que os autores, Hunt (2010), Azevedo (1999), Lajolo (2009), Miall e Kuiken (1999) e Souza (1999) criticam. Sendo assim, torna-se importante destacar que reconhecemos a necessidade de trabalhar com os diferentes gêneros textuais, no entanto, aqueles que não são ficcionais servem para outros fins, mas não para a formação literária (AZEVEDO, 1999). A produção da versão online da história O Menino Maluquinho online utiliza pouco os recursos que as TDICs possibilitam. Sua linguagem verbal é linear e não tem interatividade com o leitor, uma vez que ele não é convidado a interagir e/ou contribuir com o texto.

\section{O site $O$ pequeno leitor na categoria educativos}

$\mathrm{Na}$ categoria educativos, escolhemos para analisar o site [http://www.opequenoleitor.com.br] que foi criado em 2010 pela redatora e publicitária Stela Greco Loducca, autora de diversos livros de literatura infantil. O pequeno leitor é um site voltado para o incentivo à leitura, endereçado a crianças de cinco a oito anos. Seu conteúdo é composto por atividades interativas, jogos, brincadeiras e a estante de histórias. Assim como muitas histórias de literatura digital dirigida às crianças, esse site também aposta na criatividade do leitor navegador por meio dos recursos tecnológicos. O site apresenta os critérios de qualidade de um site educativo parcialmente, visto que encontramos fragilidade no aspecto gráfico e a falta de interatividade do leitor com os textos. Em relação à linguagem verbal das histórias disponíveis na página online, podem ser consideradas como textos infantis online, ou seja, com fins utilitários e objetivos de transmitir informação. 


\section{Algumas considerações}

As análises realizadas nos três sites educativos permitiram perceber algumas características presentes nos sites destinados ao público infantil. Todos os três são produzidos no Brasil, têm o cuidado com a produção e qualidade das atividades, não têm nenhum tipo de publicidade, e são de acesso livre e gratuito.

Os critérios defendidos por Carvalho (2006) permitiu-nos um resultado descritivo dos sites e suas estruturas. Entre os nove critérios de qualidade de um site educativo proposto pela autora, cinco tiveram resultados mais satisfatórios, a saber: identidade, usabilidade, rapidez de acesso e informação. Os critérios edição colaborativa, espaço de partilha e comunicação nas três páginas analisadas não foram contemplados, não existe espaço para enviar sugestões de melhoria da página, não dispõem de ferramentas para contato online, apenas o contato por $e$ mail. Itens que, para Carvalho (2006), são muito importantes quando se refere a um site educativo para verificar sua validade e confiabilidade.

Seguindo os estudos que nos apoiamos para este trabalho, verificando como o literário se evidencia nos sites analisados, consideramos que se ele apresenta de forma parcial, pois encontramos algumas dificuldades. Com exceção do site de Angela Lago, os outros não utilizam de forma satisfatória os recursos específicos das TDICs para apresentar de forma inovadora e interativa o texto de LI online, devido à linguagem verbal encontrada nos textos, são "linguagens meramente portadoras" (HUNT 2010, p. 158), ou seja, a linguagem escrita vinculada às propostas fragmentadas da leitura com fins utilitários ou pedagógicos, se diferenciam das impressas apenas pelo uso do suporte do meio digital. A leitura do (hiper)texto é diferente da leitura do livro impresso e requer habilidades diferentes, e quando o leitor criança tem acesso a textos online sem as características que esse meio oferece, acaba distanciando e desestimulando a leitura.

A cada leitura e análise dos sites fomos compreendendo a importância do contato do leitor com textos literários online com qualidade literária para sua formação leitora. As discussões em diálogo com os estudiosos que embasaram esta pesquisa nos mostram o quanto a literatura infantil online pode ser uma aliada no que diz respeito a formação de leitores. Porém, nos sites brasileiros e gratuitos analisados percebemos em alguns casos que o texto de LI online se apresenta com pouca criatividade e inovação, tornando necessário um olhar 
crítico e atento em relação à utilização desse material quando o objetivo for incentivar a leitura dos pequenos leitores.

Desse modo, precisamos de produção literária online para a infância de qualidade com variedade, pois as TDICs estão em constante mudança, sendo importante destacar que por mais que vivemos a era da tecnologia digital, as oportunidades de acesso dessas tecnologias não são iguais para todos. Sendo assim, é necessário criar e recriar propostas para atrair esse leitor, proporcionando autonomia e ampliando a vivência e experiências desse com a literatura. O desafio consiste em melhorar o contato do ciber(leitor) com o texto literário infantil online.

\section{REFERÊNCIAS}

AMARILHA, Marly. Apresentação. In: AMARILHA, Marly (Org.) Educação e leitura: novas linguagens, novos leitores. Campinas, SP: Mercado de Letras, 2012. p.7-11.

AZEVEDO, Ricardo. Livros para crianças e literatura infantil: convergências e dissonâncias. Jornal do alfabetizador, Porto Alegre, v. 11, n. 61, 1999. Disponível em: www.ricardoazevedo.com.br. Acesso em: 15 mar. 2016.

CARVALHO, Ana Amélia Amorim. Indicadores de qualidade de sites educativos. Cadernos SCAUSEF, Braga, PT, n. 2, p. 55-78, 2006. Disponível em: [https://repositorium.sdum.uminho.pt/bitstream/1822/5922/1/Indicadores\%20de\%20Qualidad e\%20de\%20Sites\%20-SACAUSEF\%20-AAC.pdf] Acesso em: 9 abr. 2015.

CUNHA, Maria Zilda. Entre livros e telas: a narrativa para crianças e jovens. Via Atlântica, São Paulo, n. 14, dez.2008. Disponível em:

[http://www.revistas.usp.br/viaatlantica/article/view/50379/54489] Acesso em: 31 mar. 2016.

CUNHA, Maria Zilda. Na tessitura dos signos contemporâneos: novos olhares para a literatura infantil e juvenil. São Paulo: Paulinas, 2009.

DEBUS, Eliane Santana Dias. Linguagem e infância III: a escrita e sua historicidade. Palhoça, SC: Unisul Virtual, 2008.

DEBUS, Eliane Santana Dias; BALSAN, Silvana Ferreira de Souza. Das tramas que entrecedem o contar histórias. Florianópolis, 2016. No prelo.

DEBUS, Eliane Santana Dias; DOMINGUES, Chirley. Branca de Neve e as sete versões: uma manifestação do insólito ficcional. In: DEBUS, Eliane; MICHELLI, Regina (Org.). Entre fadas e bruxas: o mundo feérico dos contos para crianças e jovens. Rio de Janeiro: Dialogarts, 2015. p. 59-73. 
ECO, Umberto. Sobre a literatura. Tradução de Eliana Aguiar. 2. ed. Rio de Janeiro: Record, 2003.

HUNT, Peter. Crítica, teoria e literatura infantil. Tradução de Cid Knipel. São Paulo: Cosac Naify, 2010.

MIALL, David S.; KUIKEN, Don.What is literariness? Three components of literary reading. Discourse Processes, Edmont, p. 121-138, 1999. Disponível em: [http://www.ualberta.ca/ dmiall/reading/Literariness.htm] Acesso em: 15 abr. 2016.

PERROTTI, Edmir. O texto sedutor na literatura infantil. São Paulo: Ícone, 1986.

SANTAELLA, Lucia. Navegar no ciberespaço: o perfil cognitivo do leitor imersivo. São Paulo: Paulus, 2004.

SOUZA, Ingobert Vargas de. Políticas públicas para o livro e a leitura no Brasil: acervos para os anos iniciais do Ensino Fundamental. 2015. Dissertação (Mestrado em Educação) Universidade Federal de Santa Catarina, Florianópolis, SC, 2015.

ZILBERMAN, Regina. A literatura infantil na escola. 11. ed. São Paulo: Global, 2003.

\section{SOBRE AS AUTORAS:}

\section{Eliane Santana Dias Debus}

Doutora em Linguística e Letras, pela Pontifícia Universidade Católica do Rio Grande do Sul (PUC/RS). Professora da Universidade Federal de Santa Catarina (UFSC), do Departamento de Metodologia de Ensino e no Programa de Pós-Graduação em Educação. Líder do Grupo de Pesquisa em Literatura Infantil e Juvenil e práticas de mediação literária (LITERALISE/UFSC). E-mail: elianedebus@hotmail.com

\section{Elika da Silva}

Mestre em Educação pela Universidade Federal de Santa Catarina (UFSC). Professora de Tecnologia Educacional na Rede Municipal de Educação de Florianópolis/SC. Integrante do Grupo de Pesquisa em Literatura Infantil e Juvenil e práticas de mediação literária (LITERALISE/UFSC). E-mail: silva.elika@gmail.com 